\title{
Introduction to the special issue in honor of William Thomson
}

\author{
Paulo Barelli ${ }^{1}$ - Youngsub Chun ${ }^{2}$ - John Duggan ${ }^{3}$
}

It is our great pleasure to present this special issue in honor of William Thomson to thank him for his enormous contributions to the theory of fair allocation.

William Thomson received his Diplôme d'Ingenieur from the Ecole Polytechnique in Paris in 1972 and his Ph.D degree in economics from Stanford University in 1976. His first appointment was at the University of Minnesota. In 1983, he joined the University of Rochester where he is currently Elmar B. Milliman Professor of Economics. He has also held various visiting appointments, mainly at Harvard University and the University of Caen. He has served on the board of editors of multiple journals, including Social Choice and Welfare since the founding of this journal, and was Editor-in-Chief of the International Journal of Game Theory from 2003 to 2008. He was President of the Society for Social Choice and Welfare from 2004 to 2006. He has supervised 52 $\mathrm{Ph} . \mathrm{D}$ students (and the number is still growing).

In the summer of 2014, a conference took place in Rochester to celebrate William's 65th birthday, and in the fall of 2014, another conference was organized in Seoul, Korea, by his former students living in Asia. To express our appreciation for his contributions to the field, we are pleased to introduce a special issue of Social Choice

\footnotetext{
$凶 \quad$ Youngsub Chun

ychun@snu.ac.kr

Paulo Barelli

paulo.barelli@rochester.edu

John Duggan

dugg@mail.rochester.edu

1 Department of Economics, University of Rochester, Rochester, NY 14627, USA

2 Department of Economics, Seoul National University, Seoul 08826, Korea

3 Wallis Institute of Political Economy, University of Rochester, Rochester, NY 14627-0158, USA
} 
and Welfare in his honor. All the papers were contributed by his students and friends, and most of them were presented at the two 2014 conferences.

This special issue consists of 11 papers on fair allocation. Due to an unfortunate mistake in the editorial process, a paper by Özgür Kibris and Arzu Kibris, entitled "On surplus-sharing in partnerships", submitted to this special issue, appeared in a regular issue of the Journal (Social Choice and Welfare (2016) 47:98-11), which consider a family of partnership agreements commonly used in real life and inquire which partnership agreements are productively efficient and which are socially efficient. We apologize.

\section{Probabilistic assignment of objects}

The first two papers deal with the probabilistic assignment of indivisible resources, or "objects", to a group of agents. In "Implementation in stochastic dominance Nash equilibria," Eun Jeong Heo and Vikram Manjunath define Nash equilibria when players base their evaluation of strategies on stochastic dominance comparisons. They study the implementability of solutions in such equilibria. They show that a Maskin-type invariance condition is necessary and sufficient for implementability. In "Efficient lottery design," Onur Kesten, Morimitsu Kurino, and Alexander S. Nesterov provide new tools for obtaining stochastic improvements in lotteries so as to facilitate the design of practical lottery mechanisms. As applications, they propose lottery mechanisms that improve upon the random serial dictatorship and a lottery representation of the serial rule.

\section{Assignment problem with money}

The next two papers consider the problem of assigning objects to a group of agents when monetary compensations are possible. In "Sharing an increase of the rent fairly," Rodrigo A. Velez characterizes the family of non-contestable budget-monotone rules for the allocation of objects when monetary transfers are possible as those obtained by maximizing a min social welfare function among all non-contestable allocations. In "No-envy and egalitarian-equivalence under multi-object-demand for heterogeneous objects", Duygu Yengin investigates the existence of allocation rules satisfying assignment-efficiency, no-envy, egalitarian equivalence, and strategy-proofness.

\section{Allocation problem with single-peaked preferences}

The next two papers are concerned with allocation among agents who have singlepeaked preferences (Sprumont 1991; Thomson 1995; Bochet et al. 2012, 2013). In "Efficient, fair, and strategy-proof (re)allocation under network constraints," Karol Flores-Szwagrzak studies an allocation problem in which a resource is available in different "types" and has to be fully allocated among agents with single-peaked preferences, but there are constraints on the types that different agents can consume. He characterizes the egalitarian trade rule on the basis of efficiency, no-envy, and strategyproofness. In "A graph theoretic approach to the slot allocation problem," Youngsub Chun and Boram Park consider the problem of assigning slots to a group of agents when slots are located along a line. Each agent has a most preferred slot and her utility is equal to her consumption of money minus the distance from her most preferred slot to her assigned slot. By representing the problem as a bipartite graph, they develop a 
simple procedure to identify all efficient assignments. They also discuss the properties of two allocation rules for the problem, the leximin rule and the leximax rule.

\section{Exploring the implications of consistency}

The next three papers deal with the consistency of allocation rules for three different types of allocation problems. Consistency says that if a solution chooses a certain alternative for some problem, then for any "reduced" problem obtained by imagining the departure of some agents with their payoffs and reassessing the situation from the viewpoint of the remaining agents, the solution should assign to the remaining agents the same thing as initially (Thomson 1990, 2014). In "Taxation and poverty," Christopher P. Chambers and Juan D. Moreno-Ternero investigate the implications of consistency together with continuity, equal treatment of equals, and composition down in the context of taxation problems (O'Neill 1982; Aumann and Maschler, 1985; Young 1987a, b, 1988, 1990; Chun 1988, 1999; Thomson 2003, 2015a, b, 2016), and characterize a large family of rules, which they call generalized equal-sacrifice rules. In "Minimal consistent enlargements of the immediate acceptance rule and the top trading cycles rule in school choice," Paula Jaramillo shows that neither of these rule is consistent. She also determines that the Pareto solution is the smallest consistent solution that contains either the immediate acceptance rule or the top trading cycles rule. In "Rationality, aggregate monotonicity and consistency in cooperative games: some (im)possibility results," Pedro Calleja and Francesc Llerena consider domains of cooperative games with transferable utility and investigate the existence of singlevalued solutions satisfying individual rationality, core selection, monotonicity, and consistency. They obtain impossibility results for the combination of core selection and complementary consistency (Moulin 1985), or project consistency (Funaki 1998), or monotonicity and max consistency (Davis and Maschler 1965). However, they derive possibility results for the combination of individual rationality, monotonicity, and project consistency.

\section{Opportunity sets and equal opportunities}

The final two papers address two different notions of equal opportunity. In "Distribution of the budget sets: an axiomatic analysis," Koichi Tadenuma and Yosheng Xu introduce three properties for distributions of opportunity sets and axiomatically characterize the distribution of budget sets in a market economy. By imposing additional equity properties, they characterize the distribution of equal-income budget sets. In "Historical discrimination and optimal remediation," Laurence Kranich analyzes an optimal remediation policy for a society that is jointly committed to ensuring equal opportunity and to increasing aggregate wealth, but is faced with the vestiges of past discrimination in the form of a historically skewed distribution of social resources. Focusing on the problem of allocating existing social inputs, he describes a general procedure for determining an optimal policy. He also demonstrates by means of an example that either of two policy instruments, directly transferring resources from the advantaged to the disadvantaged or affording preferential treatment in employment to the disadvantaged group (affirmative action), might constitute an optimal remediation policy. 
We hope that William will continue his research for many years to come and supervise many more students. Also, we all wish William and Suzanne a healthy and happy life.

\section{References}

Aumann RJ, Maschler (1985) Game theoretic analysis of a bankruptcy problem from the Talmud. J Econ Theory 36:195-213

Bochet O, İlkiliç R, Moulin H, Sethuraman J (2012) Balancing supply and demand under biilateral constraints. Theor Econ 7:395-423

Bochet O, İlkiliç R, Moulin H (2013) Egalitarianism under earmark constraints. J Econ Theory 148:535-562

Chun Y (1988) The proportional solution for rights problems. Math Soc Sci 15:231-246

Chun Y (1999) Equivalence of axioms for bankruptcy problems. Int J Game Theory 28:511-520

Davis M, Maschler M (1965) The kernel of a cooperative game. Naval Res Logist Q 12:223-259

Funaki Y (1998) Dual axiomatizations of solutions of cooperative games. Mimeo, Tokyo

Moulin H (1985) The separability axiom and equal sharing methods. J Econ Theory 36:120-148

O’Neill B (1982) A problem of rights arbitration from the Talmud. Math Soc Sci 2:345-371

Sprumont Y (1991) The division problem with single-peaked preferences. Econometrica 59(2):509-519

Thomson W (1990) The consistency principle. In: Ichiishi T, Neyman A, Tauman Y (eds) Game theory and applications. Academic Press, New York, pp 187-215

Thomson W (1995) Axiomatic analysis of generalized economies with single-peaked preferences (revised 2009)

Thomson W (2003) Axiomatic and game-theoretic analysis of bankruptyc and taxation problems: a survey. Math Soc Sci 45:249-297

Thomson W (2014) Consistent Allocation Rules, Cambridge University Press, forthcoming

Thomson W (2015a) Axiomatic and game-theoretic analysis of bankruptyc and taxation problems: an update. Math Soc Sci 74:41-59

Thomson W (2015b) For claims problems, compromising between the proportional and constrained equal awards rules. Econ Theory 60:495-520

Thomson W (2016) How to Divide when there isn't Enough: from the Talmud to Game Theory, Cambridge University Press, forthcoming

Young HP (1987a) On dividing an amount according to individual claims or liabilities. Math Oper Res $12: 398-414$

Young HP (1987b) Progressive taxation and the equal sacrifice principle. J Publ Econ 32:203-214

Young HP (1988) Distributive justice in taxation. J Econ Theory 44:321-335

Young HP (1990) Progressive taxation and equal sacrifice. Am Econ Rev 80:253-266 